\title{
DELAYED LOCAL METASTASIS IN A CHOROIDAL MELANOMA*
}

\author{
BY \\ R. J. MCWILLIAM \\ Eye Infirmary, Glasgow
}

THE prognosis following apparently complete removal of an intra-ocular malignant melanoma must always be uncertain. Most recurrences, local or generalized, occur within 1 to 2 years but in a proportion there is a delay of 5 to 10 years, and quiescent periods of up to 30 years have been recorded (Duke-Elder, 1940). In the case here reported, a local recurrence occurred after a delay of 16 years.

\section{Case Report}

A policeman aged 32 years was first seen in October, 1942, complaining of blurring of the vision of the right eye of 6 months' duration.

In this eye the visual acuity was $1 / 60$ and there was a solid detachment of the retina.

The eye was enucleated in November, 1942. Pathological examination showed a shallow choroidal tumour overlying the optic nerve, about $10 \mathrm{~mm}$. in diameter by $3 \mathrm{~mm}$. in greatest depth. Microscopic sections showed a mixed-cell melanotic growth with intra-scleral extension close to the nerve. The nerve itself was not invaded although the tumour was in close contact with it at the disc.

The patient returned in January, 1957, complaining of pain above the right socket. Examination revealed a very small, non-pigmented raised area in its lower part. $X$-ray films of the orbit and skull showed no evidence of metastases. The patient, did, however have sinusitis and when this cleared his symptoms were completely relieved. No change occurred in the size or appearance of the swelling in the orbit after repeated observations over 3 months. The patient failed to keep a subsequent appointment and was not seen again until March, 1958, almost a year later. There was now a large pigmented mass in the orbit, and exenteration with immediate skin grafting was performed in April, 1958. A year later the man was alive and well, the socket was healthy, and he was wearing a prosthesis.

Examination of the material obtained at the second operation showed a hard mass, roughly $3 / 4^{\prime \prime}$ diameter in all planes, lying in the lower, posterior part of the socket. There was no evidence on palpation of any other nodule. On section the mass was found to have a thin capsule with pigmented tumour tissue inside. Microscopic sections revealed a very heavily pigmented malignant melanoma. Bleached sections showed that the cell structure was of mixed type similar to that of the mass removed 16 years previously.

I am indebted to Dr. J. Marshall and to Dr. J. Pendleton White for permission to report this case which was under their care, and to Mr. McGibbon for his technical assistance.

\section{REFERENCE}

Duke-Elder, S. (1940). “Text-book of Ophthalmology”, vol. 3, p. 2515. Kimpton, London. 